\title{
Acute exercise and hormones related to appetite regulation: a meta-analysis
}

\author{
Matthew M. Schubert ${ }^{1}$, Surendran Sabapathy ${ }^{2}$, Michael Leveritt ${ }^{3}$, and Ben Desbrow ${ }^{1}$
}

$1=$ School of Public Health

$2=$ School of Rehabilitation Sciences $\quad 3=$ School of Human Movement Studies

Research Centre for Health Practice Innovation $\quad$ University of Queensland

Griffith Health Institute St. Lucia, QLD

Griffith University Australia

Southport, QLD

Australia

Running Head: Exercise effects on appetite hormones

Acknowledgements: The authors declare no conflict of interest. No funding was obtained for this review. The authors would like to express extreme gratitude to several authors cited herein for providing access to data. The authors would also like to thank the reviewers for their constructive comments that improved the manuscript.

Corresponding author:

Matt Schubert $\quad$ P: +61 (07)5552 7708

School of Rehabilitation Sciences $\quad$ F: +61 (07)5552 8799

Griffith University ～E-mail:

Southport, QLD 4222 
Captions \& legends for figures

Figure 1: Flowchart of study selection

Figure 2: Forest plot of effect size (means $\pm 95 \% \mathrm{CI}$ ) for studies evaluating acylated ghrelin area under the concentration-time curve (AUC)

Figure 3: Forest plot of effect sizes (means $\pm 95 \% \mathrm{CI}$ ) for studies evaluating peptide $\mathrm{YY}$ area under the concentration-time curve (AUC)

Figure 4: Forest plot of effect sizes (means $\pm 95 \% \mathrm{CI}$ ) for studies evaluating glucagon-like peptide 1 (GLP-1) area under the concentration-time curve (AUC)

Figure 5: Forest plot of effect sizes (means $\pm 95 \% \mathrm{CI}$ ) for studies evaluating pancreatic polypeptide (PP) area under the concentration-time curve (AUC) 


\section{Structured Abstract}

BACKGROUND: Understanding the impact of an acute bout of exercise on hormones involved in appetite regulation may provide insight into some of the mechanisms regulating energy balance. In resting conditions, acylated ghrelin is known to stimulate food intake, while hormones such as peptide YY (PYY), pancreatic polypeptide (PP), and glucagon-like peptide 1 (GLP-1) are known to suppress food intake. OBJECTIVE: The objective of the present review was to determine the magnitude of exercise effects on levels of gastrointestinal hormones related to appetite using systematic review and meta-analysis. Additionally, factors such as exercise intensity, duration, and mode, in addition to participant characteristics, were examined to determine their influence on these hormones. DATA SOURCES: Major databases (PubMed, Scopus, Google Scholar, Science Direct, Academic Search Premier, \& EBSCOHost) were searched, through February 2013, for original studies, abstracts, and dissertations that examined responses of appetite hormones to acute exercise. STUDY SELECTION: Studies were included if they evaluated appetite hormone responses during and in the hours after an acute bout of exercise and reported area under the concentration-time curve (AUC) values for more than 3 data points. Studies reporting mean or pre/post-values only were excluded. STUDY APPRAISAL \& SYNTHESIS: Initially, 75 studies were identified. After evaluating study quality and validity using the Physiotherapy Evidence Database scale, data from 20 studies (28 trials) involving 241 participants (77.6\% men) had their data extracted for inclusion in the meta-analyses. A randomeffects meta-analysis was conducted for acylated ghrelin ( $\mathrm{n}=18$ studies, 25 trials) and PYY ( $\mathrm{n}=$ 8 studies, 14 trials), with sub-group analyses and meta-regressions conducted for moderator variables. Due to a limited number of studies, fixed-effects meta-analyses were performed on PP ( $\mathrm{n}=4$ studies, 5 trials) and GLP-1 ( $\mathrm{n}=5$ studies, 8 trials) data. RESULTS: Results of the metaanalyses indicated exercise had small to moderate effects on appetite hormone levels, 
suppressing acylated ghrelin (Effect size (ES), Cohen's $d,=-0.20,95 \%$ CI $=-0.373$ to -0.027 ;

median decrease $16.5 \%)$ and increasing PYY (ES $=0.24,95 \% \mathrm{CI}=0.007$ to 0.475 ; median increase 8.9\%), GLP-1 (ES = 0.275, 95\% CI: -0.031 to 0.581 ; median increase $13 \%$ ), and PP (ES $=0.50,95 \%$ CI: 0.11 to 0.89 ; median increase $15 \%)$. No significant heterogeneity was detected in any meta-analysis (using Cochrane's $Q$ and $I^{2}$ ); however, publication biases were detected for all analyses. No moderator variables were observed to moderate the variability among the studies assessing acylated ghrelin and PYY. LIMITATIONS: The majority of the present literature is acute in nature; therefore longer term alterations in appetite hormone concentrations and their influence on food and beverage intake are unknown. Furthermore, our review was limited to English language studies and studies reporting AUC data. CONCLUSIONS: An acute bout of exercise may influence appetite by suppressing levels of acylated ghrelin while simultaneously increasing levels of PYY, GLP-1, and PP, which may contribute to alterations in food and drink intake after acute exercise. Further longitudinal studies and exploration into mechanisms of action are required to determine the precise role these hormones play in the longterm appetite responses to an exercise intervention. 


\section{Introduction}

At the physiological and cellular level, human appetite and food intake are regulated by the neuroendocrine system [1]. Hormones secreted by the gastrointestinal tract work as regulators of appetite and food intake through mediating hunger and satiety [1-3]. Of these hormones, ghrelin, is the only known orexigenic peripheral peptide, being predominantly secreted by the gastric oxyntic cells and endocrine glands of the gastric mucosa [4]. Ghrelin exists in its total form, its acylated form, and its des-acylated form [5]. While only about 10$20 \%$ of circulating ghrelin is acylated ghrelin, this form is believed to be responsible for appetite stimulation [5-7]. Acylated ghrelin is of particular interest because it appears to be more susceptible to acute manipulation of energy balance through energy deficits or macronutrient ingestion [8]. Acylated ghrelin has only been able to be accurately measured since $\sim 2005$, and since then has been examined extensively to elucidate its precise role in appetite regulation.

Acting in opposition to acylated ghrelin are a number of anorexigenic gastrointestinal hormones. These hormones include peptide tyrosine-tyrosine (PYY), pancreatic polypeptide (PP), glucagon-like peptide 1 (GLP-1), cholecystokinin (CCK). GLP-1 is formed by proteolytic cleavage in the L cells of the gut, and is the most powerful incretin hormone $[9,10]$. GLP-1 also influences glucose homeostasis, gastric emptying, insulin secretion, and control of food intake [11]. PP is released by pancreatic F cells in response to vagal sensing, CCK and ghrelin concentrations, and sympathetic nervous system activation $[12,13]$. Its major physiological role is to reduce food intake by delaying gastric emptying and motility via inhibition of pancreatic secretions and gallbladder motility $[12,13]$. PYY is a member of the pancreatic polypeptide-fold family, and is produced by the intestinal L-cells [4, 14]. PYY has two major forms, PYY ${ }_{1-36}$ and 
$\mathrm{PYY}_{3-36}$, with $\mathrm{PYY}_{3-36}$ being the predominant circulating form and playing a greater role in appetite regulation - in particular satiety and meal termination [15]. Similar to other gastrointestinal satiety hormones (GLP-1, PP, CCK), PYY levels react to energy balance or macronutrient ingestion, increasing after a meal while causing a delay in gastric emptying, thereby prolonging feelings of satiety and fullness [14, 16, 17].

The effect of exercise on these hormones, and energy intake, has been extensively studied throughout the past decade [18-27]. Although there is no definitive consensus, there is evidence suggesting that concentrations of plasma acylated ghrelin are suppressed after strenuous endurance exercise, while concentrations of anorexigenic hormones (PYY, PP, and GLP-1) are increased $[26,28,29]$. These hormonal changes have been demonstrated to track with associated changes in appetite at rest (as assessed using subjective visual analogue scales for feelings such as hunger, fullness, satisfaction, and prospective food consumption), and may provide a potential mechanism for alterations of appetite or food and beverage intake post-exercise [19, 29, 30].

Characteristics of the exercise interventions that have examined alterations in appetite hormones have varied considerably. Most studies have utilised moderate to vigorous cycling or running at intensities ranging from $50-75 \%$ maximal oxygen uptake $\left(\dot{\mathrm{V}}_{2 \max }\right)$ and lasting approximately one hour [21, 22, 25, 26, 29, 31, 32]. Other modes of activity, such as swimming [33], resistance exercise [28, 34], and sprint interval training [35] have also been evaluated. Additionally, most of these studies have utilised relatively small sample sizes. Finally, previous reviews have been narrative in nature $[18,19]$.

With these factors in mind, a systematic review and meta-analysis on existing data is necessary to specifically examine how bouts of acute exercise impact hormonal markers related to appetite. This will provide quantification of the changes in appetite-regulating hormone levels 
after acute exercise, and could also determine which study characteristics may best explain these observed changes. Our purpose, therefore, was to conduct a meta-analysis on data from studies that have examined the effect of an acute bout of exercise on acylated ghrelin, PYY, PP, and GLP-1 concentrations. These hormones were selected over others (such as leptin) due to knowledge, as evidenced in the existing literature, that they respond to stimuli such as acute perturbations in energy balance. While there are other hormones involved in appetite regulation and energy balance, these particular hormones have the strongest literature base at the present time. Acylated ghrelin is particularly important because it is the only known peripheral hormone to stimulate feeding behaviour. Hormones related to satiety, such as PYY, PP, and GLP-1, are also important to examine because changes in these hormones may lead to alterations in gastrointestinal physiology that may contribute to alterations in feeding. Using sub-group analyses and meta-regression, we also hoped to identify which study characteristics could explain the variation among results and best predict changes in hormone levels. The outcomes from this meta-analysis may serve to better inform researchers on what is known about the effects of exercise on appetite-regulating hormones, and may provide mechanistic insight into exercise-induced alterations in food and beverage intake.

\section{Methods}

\subsection{Study selection and inclusion criteria}

Major research databases (PubMed, Scopus, EBSCOHost, Google Scholar, Academic Search Premier, ScienceDirect, \& SpringerLink) were searched from July 1, 2012 through February 1, 2013. Keyword searches were performed for “exercise”, “physical activity”, “energy expenditure”, “energy intake”, “appetite”, “hunger”, “food intake”, “acylated ghrelin”, 
“peptide YY”, “PYY”, “glucagon-like peptide 1”, “GLP-1”, “pancreatic polypeptide”, and "PP” (Electronic Supplementary Material, Search Strategy). Potential studies were identified by examining the abstracts and full-text copies were obtained if they met the initial criteria of evaluating appetite hormone changes in response to an acute exercise bout. Guidelines from the PRISMA Statement (Preferred Reporting in Systematic Reviews and Meta-Analyses) were followed in preparation of this paper, including a checklist for reporting systematic reviews and meta-analyses (Electronic Supplementary Material, PRISMA checklist) [36].

Participants in the studies were required to be non-smoking adults (lean, overweight, and/or obese), without a history of chronic disease and lacking contraindications to exercise. Selection criteria were not limited by study duration or observation time post-exercise. Study selection was also not limited by a set intensity or duration of the exercise bout, nor was inclusion constrained by exercise modality. Food intake during the observation period was permitted, and we report data on food intake responses to acute exercise bouts elsewhere [37]. For the majority of the studies that evaluated food intake $(n=18)$, the observation period ended prior to meal consumption $(n=10)$. For the remaining studies, meals were either standardised between conditions ( $(\mathrm{n}=2)$, were a combination of standardised and ad libitum meals $(\mathrm{n}=2)$, or offered ad libitum meals $(\mathrm{n}=4)$. The final six studies were examined to determine if changes in food intake at the ad libitum meals may have altered the hormone data, but no differences in food intake at individual meals were reported between the exercise and control trials [20-23, 38, 39].

All studies were required to have a control condition for inclusion and were required to employ trial order randomisation. The control condition was required to be the same as the exercise condition with regards to protocol, minus the exercise bout. Studies were included if they had more than 3 data points over time and the authors utilised area under the concentration- 
time curve (AUC) for analysis, since it is the most widely used tool when examining hormonal changes over time. In this situation, the area of a particular hormone is calculated by plotting hormonal concentrations against time (the observation period) and using the trapezoidal rule. Although AUC is a common metric for reporting hormone concentrations by time, the methods of calculating AUC can be variable depending on the sampling rate, whether AUC considers total or above/below baseline values only, and how researchers divide their “data-bins” during analysis. This led to a large variation in AUC values between studies for similar periods of time (Table 1).

Since the interventions were exercise bouts, investigators were not blinded. Studies were included if published in peer-reviewed journals, or were available as conference proceedings, theses, and dissertations. We chose a broad range of sources for study inclusion to minimise the risk of publication bias, which can occur if only published studies are included (given that studies with larger effect sizes are more likely to be published in the peer-reviewed literature) [36].

\subsection{Exclusion criteria}

Studies were excluded from further analysis if they did not measure or report AUC data for acylated ghrelin, PYY, GLP-1, and/or PP in response to an exercise bout. Studies were also excluded if they lacked a control trial. In the event that a study reported hormone data in graphical form and/or did not report a standard deviation (SD), the corresponding author was contacted to request the raw data for synthesis. Studies that examined environmental factors had their data extracted for control and normal/neutral exercise conditions only [25, 40]. 


\subsection{Data synthesis}

Once studies were obtained, they were assessed for quality and validity independently by two authors (MS \& ML) using established criteria (Physiotherapy Evidence Database-PEDro, http://www.pedro.org.au/english/downloads/pedro-scale/ [41]), with a third reviewer (BD) obtained if there was a discrepancy between scores. Inter-rater reliability and agreement were reported as Cohen's kappa [42]. The following data were extracted by one author (MS) into a computerised spreadsheet: name of first author and study publication year, hormone AUC data

$\left(\mathrm{pmol} \cdot \mathrm{L}^{-1} / \mathrm{h}, \mathrm{pg} \cdot \mathrm{mL}^{-1} / \mathrm{h}\right)$ for exercise and control conditions, gross exercise energy expenditure (ExEE), sample size, participant characteristics, blood analytical methods, information about meals provided, and exercise intervention information.

In studies that reported hormone values in $\mathrm{pmol} \cdot \mathrm{L}^{-1}$, values were converted to $\mathrm{pg} \cdot \mathrm{mL}^{-1}$ as follows: multiplied by 4 for PYY, 3.38 for acylated ghrelin, 3.297 for GLP-1, and 2.39 for PP. Standard error of the measurement (SEM) was converted to SD. All descriptive data are reported as ranges with median values.

\subsection{Meta-analysis procedures}

Upon data extraction, all data were entered into software designed specifically for metaanalyses (Comprehensive Meta-Analysis, version 2; Biostat, Englewood, NJ). The data inputted included the sample sizes, AUCs for the control and exercise conditions with their respective SDs, and mean differences between control and exercise trials. The software calculated the standardised difference in means to determine the effect size (ES) as Cohen's $d$ for each study; additionally, Hedge's $g$ was used to account for potential bias due to the small sample sizes in the reviewed studies. There were no differences between Hedge's $g$ or Cohen's 
$d$, so we report Cohen’s ES values only. Overall ES for acylated ghrelin and PYY were calculated using a random-effects model that accounts for true variation in effects occurring from study to study, as well as random error within a single study. The random effects model was chosen over a fixed-effect model because experimental factors such as ExEE and intensity varied considerably among studies, and a random-effects model better accounts for these variations during analysis [43]. Due to a smaller number of studies $(\mathrm{n}<10)$, we utilised fixed-effects modelling for the analysis of GLP-1 and PP; however, the data yielded no difference between fixed- or random-effects modelling for these hormones.

In accordance with Cohen (1992), we interpreted ES of $<0.2$ as trivial, $0.2-0.3$ as small, $0.4-0.8$ as moderate, and $>0.8$ as large [44]. A negative ES value indicates that exercise was associated with decreased hormone levels, while a positive ES indicates that hormone levels increased with exercise.

Heterogeneity was calculated as Cochrane’s $Q$ and the $I^{2}$ index. Values of 25\%, 50\%, and $75 \%$ were used for the $I^{2}$ analysis, and correspond to low, moderate, and high heterogeneity, respectively [45]. For Cochrane’s $Q$, significant heterogeneity is considered to exist when the $Q$ value exceeds the degrees of freedom $\left(d_{f}\right)$ of the estimate [46]. Sensitivity analyses were conducted by excluding one study at a time to examine if results were driven by any one study.

To assess whether differences in experimental design could explain the variation in ES between the studies evaluating acylated ghrelin and PYY, we performed sub-group metaanalyses and/or meta-regressions (method-of-moments model), as has been performed previously [37]. This analysis included meta-regressions of continuous data, such as energy expenditure of exercise, exercise duration, exercise intensity, body mass index (BMI), and length of AUC observation time. Sub-group meta-analyses were conducted for categorical data, such as 
exercise mode, fed state, sex (men, women, or both), and hormone analytical method (enzymelinked immunosorbent assay (ELISA), radioimmunoassay (RIA), or Multiplex).

Publication bias was assessed utilising funnel plots, as previously described [37]

(Electronic Supplementary Material, Figures S1-4). If there is no publication bias, studies should be distributed evenly around the mean ES because of random sampling error. The trim-and-fill correction described by Duval and Tweedie was used to assess bias [47]. This technique allows for the computation and inclusion of potentially missing studies to create symmetry about the overall mean ES.

Statistical significance was set at $p<0.05$ in a Z-test analysis. The Z-tests were utilised to examine if ES were significantly different from zero.

\section{Results}

\subsection{Overview}

Figure 1 presents the decision tree of study selection. In total, 75 studies were initially identified. After filtering, 20 studies met inclusion criteria for the meta-analyses. All studies were published, or had been accepted for publication, in peer-reviewed, scientific journals. In summary, the experimental trials within the studies were conducted over the course of several hours, and generally began with participants either ingesting a standardised breakfast meal (providing either an absolute amount of energy or a relative amount of carbohydrate (CHO), set as $\mathrm{g} \mathrm{kg}^{-1}$ body mass) followed by a bout of exercise, or a bout of exercise in the fasted state. Throughout the trials, blood samples were taken at regular intervals. 
[Insert Figure 1 here]

The studies on acute exercise and changes in appetite-related hormones are summarised in Table 1. Multiple studies utilised more than one category of participants: lean vs. obese, runners vs. walkers, and men vs. women [26, 32, 48]; or different modes or intensities of exercise [28, 34, 49, 50]. Therefore, these studies were reported as two trials. When accounting for differences, this raised the total number of trials to 28, each with an exercise and control condition. In summary, 18 studies (25 trials) reported acylated ghrelin AUC data, 9 studies (14 trials) reported PYY AUC data, 5 studies (8 trials) reported GLP-1 AUC data, and 4 studies (5 trials) reported AUC data for PP. Eleven of the 28 trials utilised cycling as the mode of exercise, 11 utilised running, 3 utilised walking, 2 utilised resistance training, and 1 utilised swimming. Fourteen of the 28 trials were conducted $1-3.5 \mathrm{hr}$ post-prandially (median $=1.75 \mathrm{hr}$ ), while the remaining 14 trials were conducted after an $8-10 \mathrm{hr}$ fast. The energy value of the pre-exercise meal ranged from $882-3423 \mathrm{~kJ}$ (median = $2345 \mathrm{~kJ}$ ). The mean PEDro score for the 20 studies was $6.08 \pm 0.63$. Cohen’s kappa, indicative of the level of agreement between reviewers (where -1.0 is perfect disagreement, 0 is random agreement/disagreement, and 1.0 is perfect agreement [42]), was equal to 0.91. All studies were generally of high quality; however, the PEDro scores may not accurately reflect this because of the inherent problem of blinding, which make up 3 of the 11 items on the PEDro checklist [41].

\subsection{Participant demographics and exercise intervention characteristics}

The majority of participants $(n=241)$ were men $(n=187 ; 77.6 \%)$, with BMI values ranging from $19.8-32.5 \mathrm{~kg} \cdot \mathrm{m}^{-2}\left(\right.$ median $\left.=23.4 \mathrm{~kg} \cdot \mathrm{m}^{-2}\right)$ and $\dot{\mathrm{V}} \mathrm{O}_{2 \max }$ values between 34 and 63 
$\mathrm{mL} \cdot \mathrm{kg}^{-1} \cdot \mathrm{min}^{-1}\left(\right.$ median $\left.=56.9 \mathrm{~mL} \cdot \mathrm{kg}^{-1} \cdot \mathrm{min}^{-1}\right)$. Aerobic exercise interventions ranged from $30-$ 120 min (median $=60 \mathrm{~min})$ at an intensity between $45-75 \% \dot{\mathrm{V}} \mathrm{O}_{2 \max }\left(\right.$ median $\left.=70 \% \dot{\mathrm{V}} \mathrm{O}_{2 \max }\right)$. Resistance exercise interventions were 45 and 90 min long, at intensities of $\sim 80 \% 10-12$ repetition maximum (protocols summarised in Table 1). Gross energy expended during the exercise bouts ranged from $600-6500 \mathrm{~kJ}$ (median $=2730 \mathrm{~kJ})$. There was a median of 11 participants per study (range $=7-21)$. The length for all trials $(n=28)$ was between $1.5-9$ hours (median $=4 \mathrm{hr})$.

\subsection{Alterations in appetite hormone levels in response to exercise}

A median $16.5 \%$ decrease was observed in median acylated ghrelin AUC values $(n=25)$ over a median 4 hour period (Control: $811 \pm 541$ v. Exercise: $696 \pm 388 \mathrm{pg} \bullet \mathrm{mL}^{-1}$ ). Conversely, median PYY AUC levels $(\mathrm{n}=14)$ increased 8.9\% over the same median 4 hour period (Control: $884 \pm 267$ vs. Exercise: $\left.970 \pm 280 \mathrm{pg} \bullet \mathrm{mL}^{-1}\right)$. Median GLP-1 AUC levels $(\mathrm{n}=8)$ increased 13.1\% over a median 2 hour period (Control: $428 \pm 186$ vs. Exercise: $493 \pm 225$ pg $\bullet \mathrm{mL}^{-1}$ ). Finally, median PP AUC levels ( $\mathrm{n}=5$ ) increased 15\% over a median 2 hour period (Control: 192 \pm 98 vs. Exercise: $\left.226 \pm 114 \mathrm{pg} \cdot \mathrm{mL}^{-1}\right)$.

[Insert Table 1 here]

\subsection{Meta-analysis}

Individual study statistics and results for each model are available in the online supplementary material (Electronic Supplementary Material, Tables S1-4). 


\subsubsection{Effect size and moderator variables for the acylated ghrelin AUC analysis}

Results of the meta-analysis indicated a small mean effect of exercise in the suppression of acylated ghrelin levels ( $E S=-0.20,95 \% \mathrm{CI}=-0.373$ to $-0.027 ; n=25$; Figure 2), which was statistically different from zero $(p=0.024)$. No significant heterogeneity among these studies

was detected $\left(I^{2}=0 \% ; Q=20.04, d_{f}=24, p=0.695\right)$. Sensitivity analysis showed minor shifts only, and these shifts did not impact overall significance of the mean effect.

Data from the analyses of moderator variables are presented in Table 2. None of the moderator variables were found to influence the variability among studies examining acylated ghrelin AUC.

Inspection of the funnel plot (Electronic Supplementary Material, Figure S1) of standard error by the ES showed a shift to the left of the mean, suggesting the presence of publication bias. Using the trim-and-fill correction, one further study that did not report exercise-induced suppression of acylated ghrelin is needed in order to bring symmetry about the mean. This study would moderate the ES to -0.17 (95\% CI: -0.34 to -0.003) while not altering the statistical significance; but it would need to have a moderate or greater ES $(\geq 0.5)$.

[Insert Figure 2 here]

\subsubsection{Effect size and moderator variables for the PYY AUC analysis}

The meta-analysis revealed a small mean effect for exercise to increase PYY AUC levels (ES $=0.24,95 \% \mathrm{CI}=0.007$ to $0.475 ; \mathrm{n}=14$; Figure 3 ), and this was significantly different from zero $(p=0.044)$. There was minimal heterogeneity among these studies $\left(I^{2}=0 \% ; Q=4.629, d_{f}\right.$ $=13, p=0.982)$. Sensitivity analysis showed that a study by Broom and colleagues’ [28] 
influenced the results toward positive values. The removal of this trial decreased the effect size to 0.20 (95\% CI: -0.04 to 0.447$)$ and also negated its significance $(p=0.102)$.

Data from the analyses of moderator variables are presented in Table 2. None of the moderator variables examined reached statistical significance.

Inspection of the funnel plot (Electronic Supplementary Material, Figure S2) of standard error by the ES showed a distribution of effect sizes to the right of the mean, suggesting a publication bias for studies revealing an exercise-mediated increase in PYY. Using the trim-andfill correction, one study with an ES between -0.3 and -0.4 would be necessary to bring symmetry about the mean. This would modify the ES accordingly (ES $=0.20,95 \%$ CI: -0.023 to 0.43 ) and negate its significance.

[Insert Figure 3 here]

[Insert Table 2 here]

\subsubsection{Effect size for the GLP-1 AUC analysis}

The meta-analysis for GLP-1 revealed a small mean effect for exercise to increase AUC levels (ES $=0.28,95 \% \mathrm{CI}$ : -0.031 to $0.581 ; n=8$; Figure 4), although this only trended towards a significant difference from zero $(p=0.078)$. There was minimal heterogeneity among these studies $\left(I^{2}=0 \% ; Q=3.934, d_{f}=7, p=0.787\right)$. Several studies moderated the results; for example, removing the study with the largest positive ES [24] would decrease the mean effect size to 0.21 (95\% CI: -0.118 to 0.54$)$ and also moderate the $\mathrm{p}$-value $(p=0.209)$. Conversely, removing the only study with a negative ES [27] would increase the mean ES to 0.417 (95\% CI: 0.069 to 0.766$)$ and also create a significant difference from zero $(p=0.019)$. 
Inspection of the funnel plot (Electronic Supplementary Material, Figure S3) of standard error by the ES showed a distribution to the right of the mean, suggesting the presence of publication bias. Given the small number of studies, this would be expected. Using the trimand-fill correction, 4 studies that do not report exercise-mediated increases in GLP-1 (with moderate ES of approximately -0.5) would be needed to create symmetry about the mean. If these studies were to be found, they would nullify the effect size (ES $=0.033,95 \%$ CI: -0.22 to $0.286)$.

\subsubsection{Effect size for the PP AUC analysis}

The meta-analysis revealed a moderate mean effect for exercise to increase PP AUC levels ( $\mathrm{ES}=0.50,95 \% \mathrm{CI}$ : 0.113 to $0.893 ; \mathrm{n}=5$; Figure 5 ), which was significantly different from zero $(p=0.011)$. Minimal heterogeneity was detected among these studies $\left(I^{2}=0 \% ; Q=\right.$ 3.567, $\left.d_{f}=4, p=0.468\right)$. Two studies with the largest ES $[24,34]$ increased the mean ES, and the removal of either study would decrease the effect size to 0.39 (95\% CI: -0.04 to 0.83 ) while moderating the significance $(p=0.078)$.

Inspection of the funnel plot (Electronic Supplementary Material, Figure S4) of standard error by the ES showed a distribution to the right of the mean, suggesting the presence of publication bias. As with GLP-1, due to the small number of studies, this would be expected. Using the trim-and-fill correction, one study that did not report an exercise-induced increase in PP (with an ES of approximately -0.25) would be necessary to create symmetry around the mean. This would moderate the ES to 0.40 ( $95 \%$ CI: 0.0376 to 0.757 ) but not alter its significance. 
[Insert Figure 4 here]

[Insert Figure 5 here]

\section{Discussion}

Examining the impact of acute exercise on levels of hormones related to appetite regulation may provide mechanistic insight into exercise-induced changes in appetite and food and beverage intake. The purpose of this article was to perform a meta-analysis to determine the efficacy of acute exercise bouts to alter hormonal mediators of appetite in the hours after exercise. We observed small to moderate changes in opposing directions for acylated ghrelin and three anorexigenic hormones (PYY, GLP-1, and PP). These results are consistent with the majority of the present literature, as well as the known actions of these hormones on appetite regulation. Acylated ghrelin is a peripheral hormone well known to stimulate hunger and food intake, while PYY, GLP-1, and PP all inhibit food intake through various mechanisms of action. Our results indicate exercise alters hormones known to influence feeding behaviour in directions that could be expected to contribute to prospective changes in food and beverage intake post-exercise, such as a transient suppression of hunger or increased feeding latency [51, $52]$.

It has been extensively speculated that exercise intensity is a factor that may influence exercise-induced suppression of acylated ghrelin [21, 29, 49]. Aside from one study [35], research has been conducted at intensities of $<75 \% \dot{\mathrm{V}}_{2 \max }$. Deighton and colleagues provide evidence that supra-maximal exercise may be more potent for suppressing acylated ghrelin than vigorous ( $\sim 68 \% \dot{\mathrm{VO}}_{2 \max }$ ) endurance exercise, although the supra-maximal sprint exercise led to higher hunger levels later in the observation period (albeit with no changes in energy intake) 
[35]. Given that sprint interval training has become of considerable interest as a time-saving alternative to endurance exercise [53], further information on the hormonal and energy intake responses to sprint- and high-intensity interval training is warranted, particularly in special populations (i.e. overweight/obese individuals, patients with diabetes).

Differences in appetite and energy intake may exist between men and women [54, 55]. In a complex crossover study, Hagobian and colleagues evaluated sex differences in hormones and energy intake in response to control conditions, 4 days of exercise with energy replacement (to maintain energy balance), and 4 days of exercise without energy replacement (energy deficit) [54]. In response to a meal tolerance test after 4 days in balance or deficit, the authors found that women had markedly higher acylated ghrelin concentrations compared to baseline, while no significant difference existed in men [54]. However, a more recent paper found that men and women did not differ in their hormonal or appetite responses to an exercise bout matched for relative energy expenditure ( $\sim 30 \%$ estimated daily EE); indeed, both sexes had significant reductions in relative energy intake post-exercise and no observable changes in appetite hormones (acylated ghrelin and $\mathrm{PYY}_{3-36}$ ) [48]. Although initial reports questioned whether long-term exercise was as effective for weight loss in women as compared to men [56, 57], recent literature has indicated that when energy expenditure is matched between sexes, differences in weight loss or energy intake do not occur $[58,59]$ - appetite hormone responses and their roles remain to be more thoroughly elucidated.

With respect to other individual differences, BMI showed no effect on the variation among the studies. The majority of the participants were young, lean individuals, with only two studies that evaluated overweight and obese individuals. Other than the fact that obese individuals appear to have a blunted post-prandial ghrelin response [60], relatively little is 
known about how exercise can influence concentrations of acylated ghrelin in obese individuals. The same holds true for anorexigenic appetite hormones, although it is known that obese individuals have lower circulating PYY levels and appear to have a deficiency in postprandial secretion [61]. Although evidence is equivocal at present, GLP-1 impairment and postprandial deficiency also can occur in the obese [62]. In support of our findings that exercise increased PYY and GLP-1 concentrations, exercise may help improve both absolute concentrations and sensitivity to PYY and GLP-1; potentially assisting obese individuals terminate meals more rapidly and maintain a longer inter-meal interval. However, this remains to be determined.

The effect of exercise mode on appetite regulation is of considerable interest due to variety in exercise training being a potentially important predictor of compliance [63, 64]. It has been speculated that studies involving exercise that induces greater metabolic and mechanical demands (potentially causing muscle damage and greater muscle loading, e.g. running) tend to more potently suppress levels of hunger and acylated ghrelin [21, 29]. One would expect acylated ghrelin suppression to be lower after running-type exercise due to altered splanchnic blood flow, which inhibits ghrelin secretion [28, 29]; however, research indicates altered blood flow also occurs after vigorous cycling [65]. Additionally, increased secretion of PYY and GLP-1 from the small intestine and PP from the pancreas could attenuate gastric motility, theoretically decreasing the desire to eat [32]. The only study directly comparing running and cycling reported no differences in acylated ghrelin levels between exercise modes at the same relative intensity [49]. The two studies evaluating resistance training found suppressed acylated ghrelin levels, while endurance exercise increased or did not alter PYY concentrations in the same studies [28, 34]. 
At this point, it would be applicable to examine the findings of the present meta-analysis in the context of the results of our previous meta-analysis on energy intake after acute exercise [37]. Twelve of the studies in the present meta-analysis were also included in the previous analysis [20-22, 33, 25-27, 32, 34, 40, 66]. In that meta-analysis, we evaluated food intake responses to acute bouts of exercise, and observed minimal changes for absolute energy intake (ES $=0.14$, mean difference $\sim 200 \mathrm{~kJ})$ and large deficits in relative energy intake (ES $=-1.35$, mean difference $\sim 2000 \mathrm{~kJ}$ ) [37]. These results suggested that in response to acute exercise, individuals did not compensate for the energy expended by increasing their food intake $2-10 \mathrm{~h}$ afterward. The changes in appetite hormones observed in the present paper may suggest that exercise-induced hormone changes may mediate food and beverage intake responses postexercise, potentially through prolonged feeding latency that may be caused by increased levels of PYY, GLP-1, and PP. While it is difficult to quantify if the changes in hormones would predict changes in energy intake, Larson-Meyer et al. [32] reported that the change in the levels of PYY and GLP-1 were associated with reductions in food intake after running and walking in women.

It must be stressed that hormones involved in appetite regulation are one aspect of a complex system that regulates human feeding behaviour. A number of other variables related to exercise have been shown to influence food and beverage intake. For example, environmental conditions can mediate hormone levels, food and beverage intake, and appetite sensations [25, 39, 40, 67]. It has also been shown that exercise alters receptivity of brain regions involved in food reward when shown images of food after exercise [68], which could influence central drive to eat. Others have reported that exercise can increase food reward and the desire for high-fat, sweet foods in some overweight/obese men and women, which may contribute to attenuations 
in weight loss through post-exercise consumption of high-energy foods [69]. Recent work has also indicated that substrate oxidation of CHO during exercise (1675 kJ @ 70\% heart rate maximum) accounts for $37 \%$ of the variance in post-exercise energy intake in overweight and obese women [70]. These same authors have also published work which shows resting metabolic rate is a significant predictor of meal size and energy intake, being predominantly driven by fat-free mass [71]. Thus, the relationships between exercise, appetite hormones, substrate oxidation during exercise, and changes in resting metabolic rate and fat-free mass in response to exercise training offer potential opportunities to explore the mechanisms of how exercise may influence food intake and energy balance. Finally, it is possible that chronic exercise alters the sensitivity to these hormones, much as exercise is known to improve insulin sensitivity [72]. Studies have reported that fasting acylated ghrelin levels increase [73] or do not change [74] after 12 weeks of aerobic or resistance exercise in overweight and obese individuals. These studies also reported no alterations in fasting levels of PYY, GLP-1, and PP [73, 74], with another study reporting no alterations in CCK after a similar aerobic exercise program [75]. However, it has been demonstrated that 12 weeks of training led to a greater amplitude of change and suppression of acylated ghrelin post-prandially, while levels of GLP-1 and PYY trended towards greater increases 1.5-2 h post-meal [73].

Determining an index of clinically meaningful changes in appetite hormone levels is challenging, as fasting levels tend to vary considerably among individuals [2, 3]. However, we examined the literature on appetite hormone responses to nutrient intake to obtain an estimate of what may be meaningful. It has been reported that acylated and total ghrelin concentrations are suppressed by $25-60 \% 1-2$ h post-meal ingestion ( 1600 - $2500 \mathrm{~kJ}$ of varying macronutrient composition) while GLP-1 and PYY concentrations increase by 20 - $40 \%$ [30, 76, 77]. 
Bearing this in mind, the exercise stimuli from the studies incorporated in this paper had comparatively smaller effects on appetite hormone levels (i.e. alterations of $\sim 9-17 \%$ ), suggesting that while these hormones are sensitive to changes in energy expenditure, they respond comparatively stronger to energy intake.

There are, of course, several limitations in our meta-analysis that warrant mention. Firstly, all studies cited herein were acute in nature, and little knowledge exists regarding hormonal responses and their contributions to feeding behaviour after exercise training, as mentioned above. Secondly, studies were limited to English language works. Thirdly, while the present hormones examined are well known mediators of appetite regulation, other hormones and non-physiological factors are involved. For example, CCK plays a major role in appetite regulation, but to our knowledge, only two studies have evaluated CCK responses to acute exercise, both in response to incremental exercise to exhaustion, with both reporting increased CCK responses immediately post-exercise and up to 2 hours afterward [78, 79]. Fourth, we cannot exclude the possibility that we were able to obtain all potentially relevant studies. Finally, at this point in time, any link between alterations in appetite hormones and changes in actual energy intake post-exercise is still tenuous and speculative, although the results of our two meta-analyses suggest a potential relationship exists.

\section{Conclusions}

This meta-analysis found that exercise may influence appetite by suppressing levels of acylated ghrelin (by 16.5\%), while simultaneously increasing levels of PYY, GLP-1, and PP (by 9,13 , and 15\%, respectively) for 2-9 hours post exercise. These changes in hormones, based on their known functions, could provide a potential explanation for alterations in food and 
beverage intake post-exercise. However, many questions still remain, and a few are mentioned below:

1) How does exercise above "maximal" intensities influence hormones?

2) How does intermittent- or game-type exercise influence hormones and appetite?

3) Do individuals of high fitness have different hormonal responses compared to those of lesser levels of fitness?

4) What role does body composition play in the hormonal responses to exercise?

5) What impacts do long-term exercise interventions, with and without weight loss, have on appetite hormones?

6) What are the precise mechanisms of action of exercise on appetite regulation? 


\section{References}

1. Murphy KG, Bloom SR. Gut hormones and the regulation of energy homeostasis. Nature. 2006;444(7121):854-9. doi:10.1038/nature05484.

2. Karra E, Batterham RL. The role of gut hormones in the regulation of body weight and energy homeostasis. Mol Cell Endocrinol. 2010;316(2):120-8. doi:10.1016/j.mce.2009.06.010.

3. Chaudhri OB, Salem V, Murphy KG, Bloom SR. Gastrointestinal satiety signals. Annu Rev Physiol. 2008;70:239-55. doi:10.1146/annurev.physiol.70.113006.100506.

4. Stanley S, Wynne K, McGowan B, Bloom S. Hormonal regulation of food intake. Physiol Rev. 2005;85:1131-58. doi:10.1152/physrev.00015.2004.

5. Delhanty PJ, Neggers SJ, van der Lely AJ. Mechanisms in endocrinology: Ghrelin: the differences between acyland des-acyl ghrelin. Eur J Endocrinol. 2012;167(5):601-8. doi:10.1530/EJE-12-0456.

6. Ghigo E, Broglio F, Arvat E, Maccario M, Papotti M, Muccioli G. Ghrelin: more than a natural GH secretagogue and/or an orexigenic factor. Clin Endocrinol (Oxf). 2005;62(1):1-17. doi:10.1111/j.1365-2265.2004.02160.x.

7. Wren AM, Seal LJ, Cohen MA, Brynes AE, Frost G, Murphy KG et al. Ghrelin enhances appetite and increases food intake in humans. J Clin Endo Metab. 2001;86(12):5992-5.

8. De Vriese C, Perret J, Delporte C. Focus on the short- and long-term effects of ghrelin on energy homeostasis. Nutrition. 2010;26(6):579-84. doi:10.1016/j.nut.2009.09.013.

9. Holst JJ. The physiology of glucagon-like peptide 1. Physiol Rev. 2007;87(4):1409-39. doi:10.1152/physrev.00034.2006. 
10. Holz GG, Chepurny OG. Glucagon-like peptide-1 synthetic analogs: new therapeutic agents for use in the treatment of diabetes mellitus. Curr Med Chem. 2003;10(22):2471-83.

11. Tang-Christensen M, Vrang N, Larsen PJ. Glucagon-like peptide containing pathways in the regulation of feeding behaviour. Int J Obes Relat Metab Disord. 2001;25 Suppl 5:S42-7. doi:10.1038/sj.ijo.0801912.

12. Kojima S, Ueno N, Asakawa A, Sagiyama K, Naruo T, Mizuno S et al. A role for pancreatic polypeptide in feeding and body weight regulation. Peptides. 2007;28(2):459-63. doi:10.1016/j.peptides.2006.09.024.

13. Simpson K, Parker J, Plumer J, Bloom S. CCK, PYY and PP: the control of energy balance. Handb Exp Pharmacol. 2012(209):209-30. doi:10.1007/978-3-642-24716-3_9.

14. Wynne K, Stanley S, McGowan B, Bloom S. Appetite control. J Endocrinol. 2005;184(2):291-318. doi:10.1677/joe.1.05866.

15. Karra E, Chandarana K, Batterham RL. The role of peptide YY in appetite regulation and obesity. J Physiol. 2009;587(Pt 1):19-25. doi:10.1113/jphysiol.2008.164269.

16. Hoentjen F, Hopman WPM, Jansen MJ. Effect of circulating peptide YY on gallbladder emptying in humans. Scand J Gastroenterol. 2001;36(10):1086-91.

17. Savage AP, Adrian TE, Carolan G, Chatterjee VK, Bloom SR. Effects of peptide YY (PYY) on mouth to caecum intestinal transit time and on the rate of gastric emptying in healthy human volunteers. Gut. 1987;28:166-70.

18. Martins C, Morgan L, Truby H. A review of the effects of exercise on appetite regulation: an obesity perspective. Int J Obes (Lond). 2008;32(9):1337-47. doi:10.1038/ijo.2008.98. 
19. Bilski J, Teległów A, Zahradnik-Bilska J, Dembiński A, Warzecha Z. Effects of Exercise on Appetite and Food Intake Regulation. Medicina Sportiva. 2009;13(2):82-94.

20. King JA, Wasse LK, Broom DR, Stensel DJ. Influence of brisk walking on appetite, energy intake, and plasma acylated ghrelin. Med Sci Sports Exerc. 2010;42(3):485-92. doi:10.1249/MSS.0b013e3181ba10c4.

21. King JA, Miyashita M, Wasse LK, Stensel DJ. Influence of prolonged treadmill running on appetite, energy intake and circulating concentrations of acylated ghrelin. Appetite. 2010;54(3):492-8.

doi:10.1016/j.appet.2010.02.002.

22. King JA, Wasse LK, Ewens J, Crystallis K, Emmanuel J, Batterham RL et al. Differential acylated ghrelin, peptide YY3-36, appetite, and food intake responses to equivalent energy deficits created by exercise and food restriction. J Clin Endocrinol Metab. 2011;96(4):1114-21. doi:10.1210/jc.2010-2735.

23. King JA, Wasse LK, Stensel DJ. The acute effects of swimming on appetite, food intake, and plasma acylated ghrelin. J Obes. 2011;2011(Article ID 351628):1-8. doi:10.1155/2011/351628.

24. Martins C, Morgan LM, Bloom SR, Robertson MD. Effects of exercise on gut peptides, energy intake and appetite. J Endocrinol. 2007;193(2):251-8. doi:10.1677/JOE-06-0030.

25. Shorten AL, Wallman KE, Guelfi KJ. Acute effect of environmental temperature during exercise on subsequent energy intake in active men. Am J Clin Nutr. 2009;90(5):1215-21. doi:10.3945/ajcn.2009.28162.

26. Ueda SY, Yoshikawa T, Katsura Y, Usui T, Nakao H, Fujimoto S. Changes in gut hormone levels and negative energy balance during aerobic exercise in obese young males. J Endocrinol. 2009;201(1):151-9. doi:10.1677/JOE08-0500. 
27. Unick JL, Otto AD, Goodpaster BH, Helsel DL, Pellegrini CA, Jakicic JM. Acute effect of walking on energy intake in overweight/obese women. Appetite. 2010;55(3):413-9. doi:10.1016/j.appet.2010.07.012.

28. Broom DR, Batterham RL, King JA, Stensel DJ. Influence of resistance and aerobic training on hunger, circulating levels of acylated ghrelin, and peptide YY in healthy males. Am J Physiol Regul Integr Comp Physiol. 2009;296(1):R29-35. doi:10.1152/ajpregu.90706.2008.

29. Broom DR, Stensel DJ, Bishop NC, Burns SF, Miyashita M. Exercise-induced suppression of acylated ghrelin in humans. J Appl Physiol. 2007;102:2165-71. doi:10.1152/japplphysiol.00759.2006.

30. Gibbons C, Caudwell P, Finlayson G, Webb DL, Hellstrom PM, Naslund E et al. Comparison of Postprandial Profiles of Ghrelin, Active GLP-1, and Total PYY to Meals Varying in Fat and Carbohydrate and Their Association With Hunger and the Phases of Satiety. J Clin Endocrinol Metab. 2013;98(5):E847-55. doi:10.1210/jc.2012-3835.

31. Becker GF, Macedo RC, Cunha Gdos S, Martins JB, Laitano O, Reischak-Oliveira A. Combined effects of aerobic exercise and high-carbohydrate meal on plasma acylated ghrelin and levels of hunger. Appl Physiol Nutr Metab. 2012;37(1):184-92. doi:10.1139/h11-149.

32. Larson-Meyer DE, Palm S, Bansal A, Austin KJ, Hart AM, Alexander BM. Influence of running and walking on hormonal regulators of appetite in women. J Obes. 2012;2012(Article ID 730409):1-15. doi:10.1155/2012/730409.

33. King JA, Wasse LK, Stensel DJ. The acute effects of swimming on appetite, food intake, and plasma acylated ghrelin. J Obes. 2011;2011. doi:10.1155/2011/351628.

34. Balaguera-Cortes L, Wallman KE, Fairchild TJ, Guelfi KJ. Energy intake and appetite-related hormones following acute aerobic and resistance exercise. Appl Physiol Nutr Metab. 2011;36(6):958-66. doi:10.1139/h11-121. 
35. Deighton K, Barry R, Connon CE, Stensel DJ. Appetite, gut hormone and energy intake responses to low volume sprint interval and traditional endurance exercise. Eur J Appl Physiol. 2012. doi:10.1007/s00421-012-25351.

36. Liberati A, Altman DG, Tetzlaff J, Mulrow C, Gotzsche PC, Ioannidis JP et al. The PRISMA statement for reporting systematic reviews and meta-analyses of studies that evaluate health care interventions: explanation and elaboration. PLoS Med. 2009;6(7):e1000100. doi:10.1371/journal.pmed.1000100.

37. Schubert MM, Desbrow B, Sabapathy S, Leveritt M. Acute exercise and subsequent energy intake. A metaanalysis. Appetite. 2012;63C:92. doi:10.1016/j.appet.2012.12.010.

38. Deighton K, Barry R, Connon CE, Stensel DJ. Appetite, gut hormone and energy intake responses to low volume sprint interval and traditional endurance exercise. Eur J Appl Physiol. 2013;113(5):1147-56. doi:10.1007/s00421-012-2535-1.

39. Wasse LK, Sunderland C, King JA, Batterham RL, Stensel DJ. Influence of rest and exercise at a simulated altitude of 4,000 m on appetite, energy intake, and plasma concentrations of acylated ghrelin and peptide YY. J Appl Physiol. 2012;112(4):552-9. doi:10.1152/japplphysiol.00090.2011.

40. Kelly PJ, Guelfi KJ, Wallman KE, Fairchild TJ. Mild dehydration does not reduce postexercise appetite or energy intake. Med Sci Sports Exerc. 2012;44(3):516-24. doi:10.1249/MSS.0b013e318231c176.

41. PEDro Scale. http://www.pedro.org.au. Accessed 15-Jul 2012.

42. Wood JM. Understanding and computing Cohen's kappa: A tutorial. Web Psych Empiricist 2007.

43. Conger SA, Warren GL, Hardy MA, Millard-Stafford ML. Does caffeine added to carbohydrate provide additional ergogenic benefit for endurance? Int J Sport Nutr Exerc Metab. 2011;21(1):71-84. 
44. Cohen J. A power primer. Psych Bull. 1992;112(1):155-9.

45. Higgins JPT, Thompson SG, Deeks JJ, Altman DG. Measuring inconsistency in meta-analysis. BMJ. 2003;327:557-60.

46. Huedo-Medina TB, Sanchez-Meca J, Marin-Martinez F, Botella J. Assessing heterogeneity in meta-analysis: Q statistic or I2 index? Psychol Methods. 2006;11(2):193-206. doi:10.1037/1082-989X.11.2.193.

47. Duval S, Tweedie R. Trim and fill: a simple funnel-plot based method of testing and adjusting for publication bias in meta-analysis. Biometrics. 2000;56(2):455-63.

48. Hagobian TA, Yamashiro M, Hinkel-Lipsker J, Streder K, Evero N, Hackney T. Effects of acute exercise on appetite hormones and ad libitum energy intake in men and women. Appl Physiol Nutr Metab. 2013;38(1):66-72. doi:10.1139/apnm-2012-0104.

49. Wasse LK, Sunderland C, King JA, Miyashita M, Stensel DJ. The influence of vigorous running and cycling exercise on hunger perceptions and plasma acylated ghrelin concentrations in lean young men. Appl Physiol Nutr Metab. 2013;38(1):1-6. doi:10.1139/apnm-2012-0154.

50. Ueda SY, Yoshikawa T, Katsura Y, Usui T, Fujimoto S. Comparable effects of moderate intensity exercise on changes in anorectic gut hormone levels and energy intake to high intensity exercise. J Endocrinol. 2009;203(3):357-64. doi:10.1677/JOE-09-0190.

51. King NA, Burley VJ, Blundell JE. Exercise-induced suppression of appetite. Effects on food intake and implications for energy balance. Eur J Clin Nutr. 1994;48(10):715-24.

52. King JA, Wasse LK, Stensel DJ. Acute exercise increases feeding latency in healthy normal weight young males but does not alter energy intake. Appetite. 2013;61(1):45-51. doi:10.1016/j.appet.2012.10.018. 
53. Astorino TA, Schubert MM. Exercise programming for cardiovascular disease. Strength Cond J. 2012;34:60-4.

54. Hagobian TA, Sharoff CG, Stephens BR, Wade GN, Silva JE, Chipkin SR et al. Effects of exercise on energyregulating hormones and appetite in men and women. Am J Physiol Regul Integr Comp Physiol. 2009;296(2):R23342. doi:10.1152/ajpregu.90671.2008.

55. Hagobian TA, Braun B. Physical activity and hormonal regulation of appetite: sex differences and weight control. Exerc Sport Sci Rev. 2010;38(1):25-30.

56. Donnelly JE, Hill JO, Jacobsen DJ, Potteiger J, Sullivan DK, Johnson SL et al. Effects of a 16-month randomized controlled exercise trial on body weight and composition in young, overweight men and women: the Midwest Exercise Trial. Arch Intern Med. 2003;163(11):1343-50. doi:10.1001/archinte.163.11.1343.

57. Donnelly JE, Smith BK. Is exercise effective for weight loss with ad libitum diet? Energy balance, compensation, and gender differences. Exerc Sport Sci Rev. 2005;33(4):169-74.

58. Caudwell P, Gibbons C, Hopkins M, King N, Finlayson G, Blundell J. No sex difference in body fat in response to supervised and measured exercise. Med Sci Sports Exerc. 2013;45(2):351-8.

doi:10.1249/MSS.0b013e31826ced79.

59. Donnelly JE, Honas JJ, Smith BK, Mayo MS, Gibson CA, Sullivan DK et al. Aerobic exercise alone results in clinically significant weight loss for men and women: Midwest exercise trial 2. Obesity (Silver Spring). 2013;21(3):E219-28. doi:10.1002/oby.20145.

60. English PJ, Ghatei MA, Malik IA, Bloom SR, Wilding JPH. Food fails to suppress ghrelin levels in obese humans. J Clin Endo Metab. 2002;87(6):2984-7.

\section{Page $\mathbf{3 1}$ of $\mathbf{4 3}$}


61. Batterham RL, Cohen MA, Ellis SM, Le Roux CW, Withers DJ, Frost GS et al. Inhibition of food intake in obese subjects by peptide YY3-36. N Engl J Med. 2003;349:941-8.

62. Madsbad S. The role of glucagon-like peptide-1 impairment in obesity and potential therapeutic implications. Diabetes Obes Metab. 2013. doi:10.1111/dom.12119.

63. Juvancic-Heltzel JA, Glickman EL, Barkley JE. The effect of variety on physical activity: a cross-sectional study. J Strength Cond Res. 2013;27(1):244-51. doi:10.1519/JSC.0b013e3182518010.

64. Glaros NM, Janelle CM. Varying the mode of cardiovascular exercise to increase adherence. J Sport Behav. 2001;24(1):42-62.

65. van Wijck K, Lenaerts K, van Loon LJC, Peters WHM, Buurman WA, Dejong CHC. Exercise-induced splanchnic hypoperfusion results in gut dysfunction in healthy men. PLoS One. 2011;6(7):e22366. doi:10.1371/journal.pone.0022366.

66. Vatansever-Ozen S, Tiryaki-Sonmez G, Bugdayci G, Ozen G. The effects of exercise on food intake and hunger: Relationship with acylated ghrelin and leptin. J Sport Sci Med. 2011;10:283-91.

67. Westerterp-Plantenga MS, Verwegen CR, Ijedema MJ, Wijckmans NE, Saris WH. Acute effects of exercise or sauna on appetite in obese and nonobese men. Physiol Behav. 1997;62(6):1345-54.

68. Evero N, Hackett LC, Clark RD, Phelan S, Hagobian TA. Aerobic exercise reduces neuronal responses in food reward brain regions. J Appl Physiol. 2012;112(9):1612-9. doi:10.1152/japplphysiol.01365.2011.

69. Finlayson G, Caudwell P, Gibbons C, Hopkins M, King N, Blundell J. Low fat loss response after medium-term supervised exercise in obese is associated with exercise-induced increase in food reward. J Obes. 2011;2011. doi:10.1155/2011/615624. 
70. Hopkins M, Blundell JE, King NA. Individual variability in compensatory eating following acute exercise in overweight and obese women. Br J Sports Med. 2013. doi:10.1136/bjsports-2012-091721.

71. Caudwell P, Finlayson G, Gibbons C, Hopkins M, King N, Naslund E et al. Resting metabolic rate is associated with hunger, self-determined meal size, and daily energy intake and may represent a marker for appetite. Am J Clin Nutr. 2013;97(1):7-14. doi:10.3945/ajcn.111.029975.

72. Shaw CS, Clark J, Wagenmakers AJ. The effect of exercise and nutrition on intramuscular fat metabolism and insulin sensitivity. Annu Rev Nutr. 2010;30:13-34. doi:10.1146/annurev.nutr.012809.104817.

73. Martins C, Kulseng B, King NA, Holst JJ, Blundell JE. The effects of exercise-induced weight loss on appetiterelated peptides and motivation to eat. J Clin Endocrinol Metab. 2010;95(4):1609-16. doi:10.1210/jc.2009-2082.

74. Guelfi KJ, Donges CE, Duffield R. Beneficial effects of 12 weeks of aerobic compared with resistance exercise training on perceived appetite in previously sedentary overweight and obese men. Metabolism. 2013;62(2):235-43. doi:10.1016/j.metabol.2012.08.002.

75. Martins C, Kulseng B, Rehfeld JF, King NA, Blundell JE. Effect of chronic exercise on appetite control in overweight and obese individuals. Med Sci Sports Exerc. 2013;45(5):805-12. doi:10.1249/MSS.0b013e31827d1618.

76. Foster-Schubert KE, Overduin J, Prudom CE, Liu J, Callahan HS, Gaylinn BD et al. Acyl and total ghrelin are suppressed strongly by ingested proteins, weakly by lipids, and biphasically by carbohydrates. J Clin Endocrinol Metab. 2008;93(5):1971-9. doi:10.1210/jc.2007-2289.

77. Bowen J, Noakes M, Trenerry C, Clifton PM. Energy intake, ghrelin, and cholecystokinin after different carbohydrate and protein preloads in overweight men. J Clin Endocrinol Metab. 2006;91(4):1477-83. doi:10.1210/jc.2005-1856. 
78. Bailey DM, Davies B, Castell LM, Newsholme EA, Calam J. Physical exercise and normobaric hypoxia: independent modulators of peripheral cholecystokinin metabolism in man. J Appl Physiol. 2001;90:105-13.

79. Sliwowski Z, Lorens K, Konturek SJ, Bielanski W, Zoladz JA. Leptin, gastrointestinal and stress hormones in response to exercise in fasted or fed subjects and before or after blood donation. J Physiol Pharmacol.

2001;52(1):53-70. 
Table 1: Effects of acute exercise on hormone area under the concentration-time curve (AUC) data

\begin{tabular}{|c|c|c|c|c|c|c|c|c|}
\hline \multirow[t]{2}{*}{ Study } & \multirow[t]{2}{*}{ Participants } & \multirow[t]{2}{*}{ Intervention } & \multirow{2}{*}{$\begin{array}{c}\text { Sampling } \\
\text { medium, AUC } \\
\text { duration, and } \\
\text { analytical method }\end{array}$} & \multicolumn{4}{|c|}{ Hormone AUC $\left(\mathrm{pg} \cdot \mathrm{mL}^{-1}\right)$} & \multirow{2}{*}{$\begin{array}{l}\text { PEDro } \\
\text { Score }\end{array}$} \\
\hline & & & & $\begin{array}{l}\text { Acylated } \\
\text { ghrelin }\end{array}$ & PYY & GLP-1 & $\mathrm{PP}$ & \\
\hline Broom et al. & 9 men & 60 min treadmill & Venous & CON: $1401 \pm$ & NM & NM & NM & 6 \\
\hline $2007^{[29]}$ & $\begin{array}{l}\mathrm{BMI}=22.2 \pm 2.1 \\
\mathrm{~kg} / \mathrm{m}^{2}\end{array}$ & $\begin{array}{l}\text { running @ 72\% } \\
\dot{\mathrm{V}} \mathrm{O}_{2 \max }\end{array}$ & $\begin{array}{c}9 \mathrm{~h} \\
\text { ELISA }\end{array}$ & $\begin{array}{l}1564 \\
\text { EX: } 917 \pm 1026^{*}\end{array}$ & & & & \\
\hline $\begin{array}{l}\text { Martins et al. } \\
2007^{[24]}\end{array}$ & $\begin{array}{l}6 \text { men \& women } \\
\text { combined BMI = } \\
22.0 \pm 3.2 \mathrm{~kg} / \mathrm{m}^{2}\end{array}$ & $\begin{array}{l}60 \text { min cycling @ } \\
65 \% \mathrm{HR}_{\max }\end{array}$ & $\begin{array}{c}\text { Venous } \\
3.5 \mathrm{~h} \\
\text { RIA }\end{array}$ & NM & $\begin{array}{l}\text { CON: } 21070 \pm \\
4652 \\
\text { EX: } 21384 \pm 5998\end{array}$ & $\begin{array}{c}\text { CON: } 24761 \pm \\
6270 \\
\text { EX: } 29306 \pm \\
7199\end{array}$ & $\begin{array}{c}\text { CON: } 11570 \pm \\
7144 \\
\text { EX: } 19770 \pm \\
10149\end{array}$ & 6 \\
\hline $\begin{array}{l}\text { Broom et al. } \\
2009^{[28]}\end{array}$ & $\begin{array}{l}11 \text { men } \\
\mathrm{BMI}=23.1 \pm 1.3 \\
\mathrm{~kg} / \mathrm{m}^{2}\end{array}$ & $\begin{array}{l}60 \text { min treadmill } \\
\text { running @ 70\% } \\
\dot{\mathrm{VO}_{2 \max }}\end{array}$ & $\begin{array}{c}\text { Venous } \\
8 \mathrm{~h} \\
\text { ELISA }\end{array}$ & $\begin{array}{l}\text { CON: } 811 \pm 852 \\
\text { EX: } 736 \pm 895\end{array}$ & $\begin{array}{l}\text { CON: } 1411 \pm 365 \\
\text { EX: } 1750 \pm 564 *\end{array}$ & NM & NM & 6 \\
\hline $\begin{array}{l}\text { Broom et al. } \\
2009-1^{[28]}\end{array}$ & $\begin{array}{l}11 \text { men } \\
\mathrm{BMI}=23.1 \pm 1.3 \\
\mathrm{~kg} / \mathrm{m}^{2}\end{array}$ & $\begin{array}{l}90 \text { min resistance } \\
\text { training } \\
10 \text { exercises, } 3 \text { sets, } \\
12 \text { reps @ 80\% 12- } \\
\text { RM }\end{array}$ & $\begin{array}{c}\text { Venous } \\
8 \mathrm{~h} \\
\text { ELISA }\end{array}$ & $\begin{array}{l}\text { CON: } 811 \pm 852 \\
\text { EX: } 696 \pm 650\end{array}$ & $\begin{array}{l}\text { CON: } 1411 \pm 365 \\
\text { EX: } 1381 \pm 322\end{array}$ & NM & NM & 6 \\
\hline
\end{tabular}




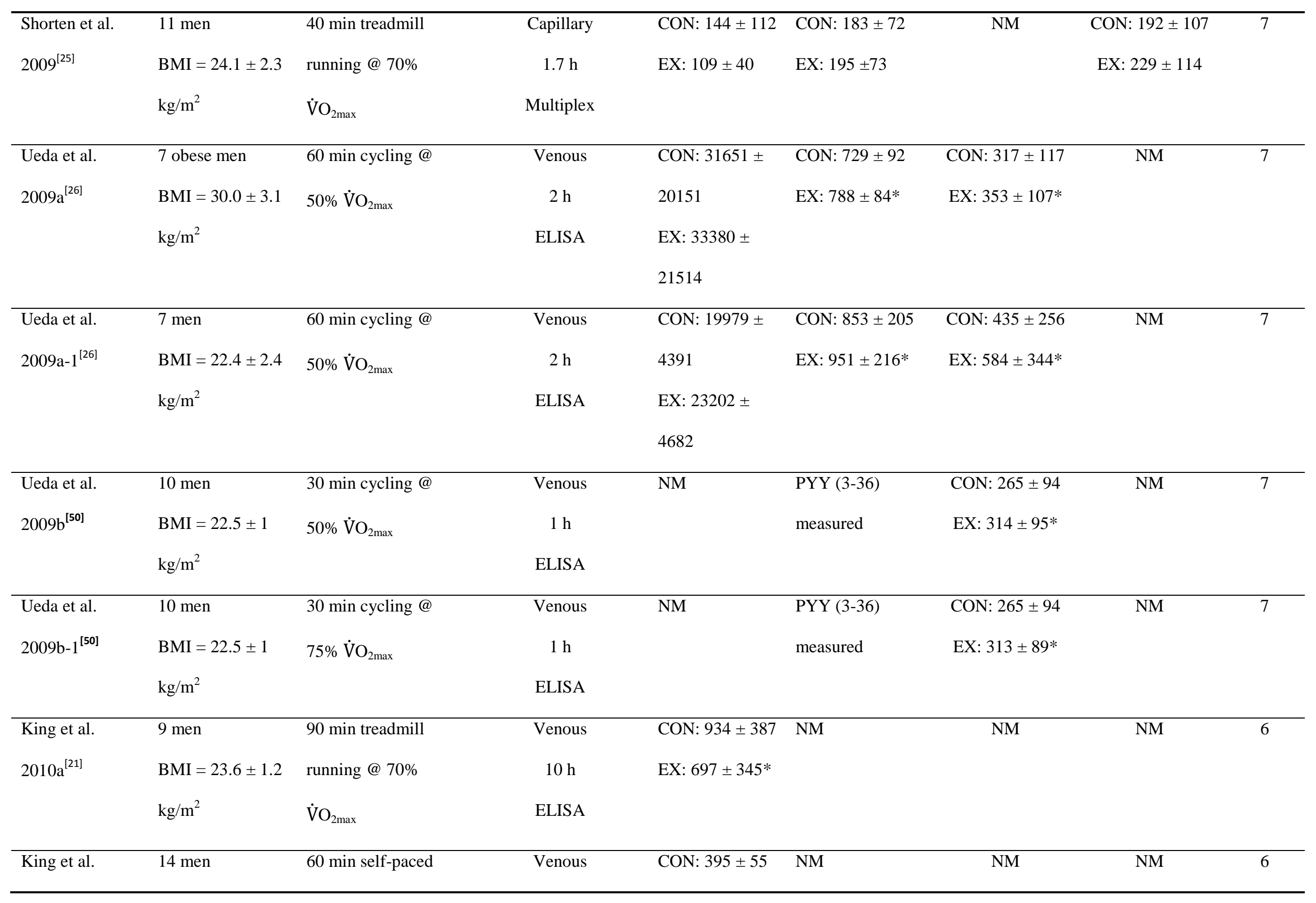




\begin{tabular}{|c|c|c|c|c|c|c|c|c|}
\hline \multirow[t]{2}{*}{$2010 b^{[20]}$} & $\mathrm{BMI}=23.4 \pm 2.2$ & "brisk walking" (7.0 & $8 \mathrm{~h}$ & \multicolumn{5}{|l|}{ EX: $390 \pm 129$} \\
\hline & $\mathrm{kg} / \mathrm{m}^{2}$ & $\begin{array}{l} \pm 0.4 \mathrm{~km} / \mathrm{hr} ; 45 \pm \\
\left.7.5 \% \dot{\mathrm{V}}_{2 \max }\right)\end{array}$ & ELISA & & & & & \\
\hline \multirow{6}{*}{$\begin{array}{l}\text { Unick et al. } \\
2010^{[27]}\end{array}$} & 19 pre- & $\sim 45$ min treadmill & Venous & CON: $13053 \pm$ & \multirow[t]{6}{*}{ NM } & CON: $423 \pm 103$ & \multirow[t]{6}{*}{ NM } & \multirow[t]{6}{*}{6.5} \\
\hline & menopausal, & walking@ @70-75\% & $3 \mathrm{~h}$ & 5901 & & \multirow{5}{*}{ EX: $402 \pm 99 *$} & & \\
\hline & overweight & $\mathrm{HR}_{\max }$ & ELISA & EX: $12721 \pm$ & & & & \\
\hline & women & & & \multirow[t]{3}{*}{6677} & & & & \\
\hline & $\mathrm{BMI}=32.5 \pm 4.3$ & & & & & & & \\
\hline & \multicolumn{2}{|l|}{$\mathrm{kg} / \mathrm{m}^{2}$} & & & & & & \\
\hline Balaguera- & 10 men & 45 min treadmill & Capillary & CON: $109 \pm 43$ & CON: $109 \pm 27$ & \multirow[t]{3}{*}{ NM } & CON: $103 \pm 85$ & \multirow[t]{3}{*}{6} \\
\hline Cortes et al. & $\mathrm{BMI}=23.7 \pm 2.0$ & running@ @0\% & $2 \mathrm{~h}$ & \multirow[t]{2}{*}{ EX: $111 \pm 68$} & EX: $112 \pm 38$ & & \multirow[t]{2}{*}{ EX: $226 \pm 152$} & \\
\hline $2011^{[34]}$ & $\mathrm{kg} / \mathrm{m}^{2}$ & $\dot{\mathrm{V}} \mathrm{O}_{2 \max }$ & Multiplex & & & & & \\
\hline Balaguera- & 10 men & $45 \min \mathrm{RT}$ & Capillary & CON: $109 \pm 43$ & CON: $109 \pm 27$ & NM & CON: $103 \pm 85$ & 6 \\
\hline Cortes et al. & $\mathrm{BMI}=23.7 \pm 2.0$ & 3 sets of 12 reps or to & $2 \mathrm{~h}$ & EX: $87 \pm 47^{*}$ & EX: $105 \pm 32$ & & EX: $115 \pm 86$ & \\
\hline \multirow[t]{2}{*}{$2011-1^{[34]}$} & $\mathrm{kg} / \mathrm{m}^{2}$ & failure of 8 exercises & \multirow[t]{2}{*}{ Multiplex } & & & & & \\
\hline & & 1 min between sets & & & & & & \\
\hline King et al. & 12 men & 90 min treadmill & Venous & CON: $1055 \pm$ & PYY(3-36) & NM & NM & 6 \\
\hline \multirow[t]{2}{*}{$2011 a^{[22]}$} & $\mathrm{BMI}=22.8 \pm 1.4$ & running @ 70\% & $9 \mathrm{~h}$ & 956 & \multirow[t]{2}{*}{ measured } & & & \\
\hline & $\mathrm{kg} / \mathrm{m}^{2}$ & $\dot{\mathrm{V}} \mathrm{O}_{2 \max }$ & ELISA & EX: $961 \pm 880 *$ & & & & \\
\hline King et al. & 14 men & 60 min intermittent & Venous & CON: $505 \pm 651$ & NM & NM & NM & 6 \\
\hline $2011 b^{[33]}$ & $\mathrm{BMI}=23.2 \pm 2.2$ & swimming [6x (7 min & $3 \mathrm{~h}$ & EX: $473 \pm 696^{*}$ & & & & \\
\hline
\end{tabular}




\begin{tabular}{|c|c|c|c|c|c|c|c|c|}
\hline & $\mathrm{kg} / \mathrm{m}^{2}$ & swim/3 min rest)] & ELISA & & & & & \\
\hline Vatansever- & 10 men & 105 min treadmill & Venous & CON: $1077 \pm 63$ & NM & NM & NM & 5.5 \\
\hline Ozen et al. & $\mathrm{BMI}=22.0 \pm 0.4$ & running@ @0\% & $4 \mathrm{~h}$ & $\mathrm{EX}: 1004 \pm 92 *$ & & & & \\
\hline \multirow[t]{2}{*}{$2011^{[66]}$} & $\mathrm{kg} / \mathrm{m}^{2}$ & $\dot{\mathrm{V}} \mathrm{O}_{2 \max }+15 \min @$ & ELISA & & & & & \\
\hline & & $70 \% \dot{\mathrm{V}} \mathrm{O}_{2 \max }$ & & & & & & \\
\hline Becker et al. & 8 men & 60 min cycling@ & Venous & CON: 96.8 & NM & NM & NM & 5.5 \\
\hline \multirow[t]{3}{*}{$2012^{[31]}$} & $\mathrm{BMI}=24 \pm 0.9$ & $70 \% \dot{\mathrm{VO}}_{2 \max }$ & $2 \mathrm{~h}$ & \pm 53.2 & & & & \\
\hline & $\mathrm{kg} / \mathrm{m}^{2}$ & & ELISA & EX: $60.7 \pm$ & & & & \\
\hline & & & & $24.3^{*}$ & & & & \\
\hline Kelly et al. & 10 men & 45 min treadmill & Capillary & CON: $152 \pm 62$ & CON: $189 \pm 35$ & $\mathrm{NM}$ & CON: $193 \pm 98$ & 7 \\
\hline \multirow[t]{2}{*}{$2012^{[40]}$} & $\mathrm{BMI}=23.9 \pm 2.1$ & running@70\% & $2 \mathrm{~h}$ & $\mathrm{EX}: 145 \pm 67$ & EX: $197 \pm 56$ & & EX: $206 \pm 88$ & \\
\hline & $\mathrm{kg} / \mathrm{m}^{2}$ & $\dot{\mathrm{V}} \mathrm{O}_{2 \max }$ & Multiplex & & & & & \\
\hline Larson-Meyer & 9 female runners & 60 min treadmill & Venous & CON: $8071 \pm$ & CON: $17040 \pm$ & CON: $5392 \pm$ & NM & 4.5 \\
\hline \multirow[t]{3}{*}{ et al. $2012^{[32]}$} & $\mathrm{BMI}=19.8 \pm 1.0$ & running@70\% & $2 \mathrm{~h}$ & 11319 & 12780 & 6088 & & \\
\hline & $\mathrm{kg} / \mathrm{m}^{2}$ & $\dot{\mathrm{V}} \mathrm{O}_{2 \max }$ & RIA & EX: $21466 \pm$ & EX: $17484 \pm$ & EX: $6323 \pm$ & & \\
\hline & & & & $17292 *$ & 19892 & 5660 & & \\
\hline Larson-Meyer & 10 female & 60 min treadmill & Venous & CON: $7744 \pm$ & CON: $13952 \pm$ & CON: $6940 \pm$ & NM & 4.5 \\
\hline \multirow[t]{3}{*}{ et al. 2012-1 ${ }^{\text {[32] }}$} & walkers & walking@ @7\% & $2 \mathrm{~h}$ & 9660 & 15232 & 6814 & & \\
\hline & $\mathrm{BMI}=22.1 \pm 3.4$ & $\dot{\mathrm{V}} \mathrm{O}_{2 \max }$ & RIA & EX: $9734 \pm$ & $\mathrm{EX}: 28008 \pm$ & EX: $8293 \pm$ & & \\
\hline & $\mathrm{kg} / \mathrm{m}^{2}$ & & & 13885 & 26948 & 8936 & & \\
\hline Wasse et al. & 10 men & 60 min treadmill & Venous & CON: $755 \pm 541$ & CON: $848 \pm 224$ & NM & NM & 6.5 \\
\hline
\end{tabular}




\begin{tabular}{|c|c|c|c|c|c|c|c|c|}
\hline \multirow[t]{2}{*}{$2012^{[39]}$} & $\mathrm{BMI}=24.8 \pm 2.4$ & running @ 70\% & $7 \mathrm{~h}$ & EX: $644 \pm 388^{*}$ & \multicolumn{4}{|l|}{ EX: $912 \pm 292^{*}$} \\
\hline & $\mathrm{kg} / \mathrm{m}^{2}$ & $\dot{\mathrm{V}} \mathrm{O}_{2 \max }$ & ELISA & & & & & \\
\hline Wasse et al. & 11 men & 60 min treadmill & Venous & CON: $606 \pm 378$ & NM & NM & NM & 5.5 \\
\hline \multirow[t]{2}{*}{$2013^{[49]}$} & $\mathrm{BMI}=23.4 \pm 2.3$ & running @ 70\% & $4 \mathrm{~h}$ & EX: $455 \pm 355^{*}$ & & & & \\
\hline & $\mathrm{kg} / \mathrm{m}^{2}$ & running $\dot{\mathrm{V}} \mathrm{O}_{2 \max }$ & ELISA & & & & & \\
\hline Wasse et al. & 11 men & 60 min cycling @ & Venous & CON: $606 \pm 378$ & NM & NM & NM & 5.5 \\
\hline \multirow[t]{2}{*}{$2013-1^{[49]}$} & $\mathrm{BMI}=23.4 \pm 2.3$ & $70 \%$ cycling $\dot{\mathrm{V}} \mathrm{O}_{2 \max }$ & $4 \mathrm{~h}$ & EX: $448 \pm 315$ & & & & \\
\hline & $\mathrm{kg} / \mathrm{m}^{2}$ & & ELISA & & & & & \\
\hline \multirow{3}{*}{$\begin{array}{l}\text { Deighton et al. } \\
2013^{[35]}\end{array}$} & 12 men & 60 minutes cycling @ & Venous & CON: $344 \pm 146$ & CON: $915 \pm 310$ & NM & NM & 5.5 \\
\hline & $\mathrm{BMI}=24.2 \pm 2.9$ & $65 \% \dot{\mathrm{V}} \mathrm{O}_{2 \max }$ & $6.25 \mathrm{~h}$ & EX: $277 \pm 112^{*}$ & EX: $1028 \pm 352$ & & & \\
\hline & $\mathrm{kg} / \mathrm{m}^{2}$ & & ELISA & & & & & \\
\hline \multirow{6}{*}{$\begin{array}{l}\text { Deighton et al. } \\
2013-1^{[35]}\end{array}$} & 12 men & 30 minutes sprint- & Venous & CON: $344 \pm 146$ & CON: $915 \pm 310$ & NM & NM & 5.5 \\
\hline & $\mathrm{BMI}=24.2 \pm 2.9$ & interval exercise: 3.5 & $6.25 \mathrm{~h}$ & EX: $237 \pm 116^{*}$ & EX: $991 \pm 269$ & & & \\
\hline & $\mathrm{kg} / \mathrm{m}^{2}$ & min warm-up, 6x 30- & ELISA & & & & & \\
\hline & & sec Wingate tests (4 & & & & & & \\
\hline & & min rest between), & & & & & & \\
\hline & & 3.5 min warm-down & & & & & & \\
\hline \multirow{4}{*}{$\begin{array}{l}\text { Hagobian et al. } \\
2013^{[48]}\end{array}$} & 11 men & Cycling @ 70\% & Venous & CON: $83213 \pm$ & PYY (3-36) & NM & NM & 6 \\
\hline & $\mathrm{BMI}=26 \pm 4$ & $\dot{\mathrm{V}} \mathrm{O}_{2 \max }$ until $30 \%$ & $2 \mathrm{~h}$ & 118573 & measured & & & \\
\hline & $\mathrm{kg} / \mathrm{m}^{2}$ & $\operatorname{EDEE}(82 \pm 13 \mathrm{~min})$ & ELISA & EX: $123914 \pm$ & & & & \\
\hline & & & & 146227 & & & & \\
\hline
\end{tabular}




\begin{tabular}{|c|c|c|c|c|c|c|c|c|}
\hline Hagobian et al. & 10 women & Cycling@ @ 70\% & Venous & CON: $53740 \pm$ & PYY (3-36) & NM & NM & 6 \\
\hline \multirow[t]{3}{*}{$2013-1^{[48]}$} & $\mathrm{BMI}=24 \pm 2$ & $\dot{\mathrm{V}} \mathrm{O}_{2 \max }$ until $30 \%$ & $2 \mathrm{~h}$ & 81063 & measured & & & \\
\hline & $\mathrm{kg} / \mathrm{m}^{2}$ & $\operatorname{EDEE}(84 \pm 17 \mathrm{~min})$ & ELISA & EX: $35121 \pm$ & & & & \\
\hline & & & & 25128 & & & & \\
\hline
\end{tabular}

Values are mean \pm SD

Studies arranged alphabetically by author by year of publication

Studies that had more than one condition or participant population have their second condition denoted by a “-1"

* = significantly different from control (as reported within studies; $p<0.05$ )

Values reported as $\mathrm{pmol} \cdot \mathrm{L}^{-1}$ were converted to $\mathrm{pg} \cdot \mathrm{mL}^{-1}$ by multiplying by 3.38 for acylated ghrelin, 4 for PYY, 3.3 for GLP-1, and 2.39 for PP.

$\mathrm{HR}_{\max }=$ Maximum heart rate BMI = Body mass index $\quad \mathrm{CON}=$ Resting control trial $\quad \mathrm{EX}=$ Exercise trial $\quad$ RT $=$ Resistance training

$\mathrm{NM}=$ Not measured $\quad$ ELISA $=$ Enzyme-linked immunosorbent assay $\quad$ RIA $=$ Radioimmunoassay $\quad$ Rep $=$ repetition

$\mathrm{RM}=$ Repetition maximum $\quad \dot{\mathrm{V}} \mathrm{O}_{2 \max }=$ Maximum oxygen uptake $\quad$ PEDro $=$ Physiotherapy evidence database scale $\quad$ PYY $=$ Peptide YY

GLP-1 = Glucagon-like peptide $1 \quad \mathrm{PP}=$ Pancreatic polypeptide $\quad$ EDEE = Estimated daily energy expenditure 
Table 2: Summary of moderator variable analysis for the acylated ghrelin and peptide YY meta-analyses by sub-group and meta-regression

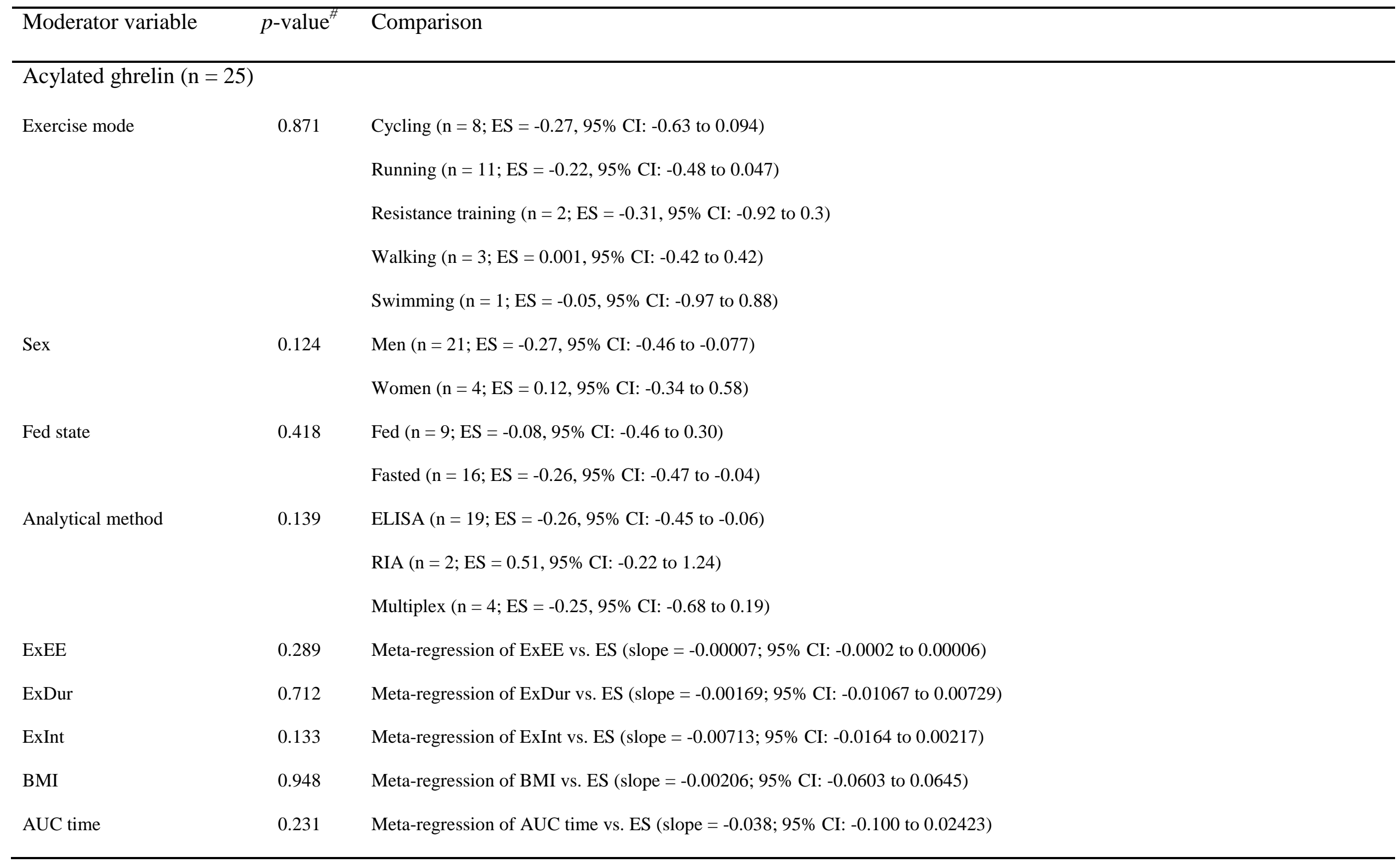




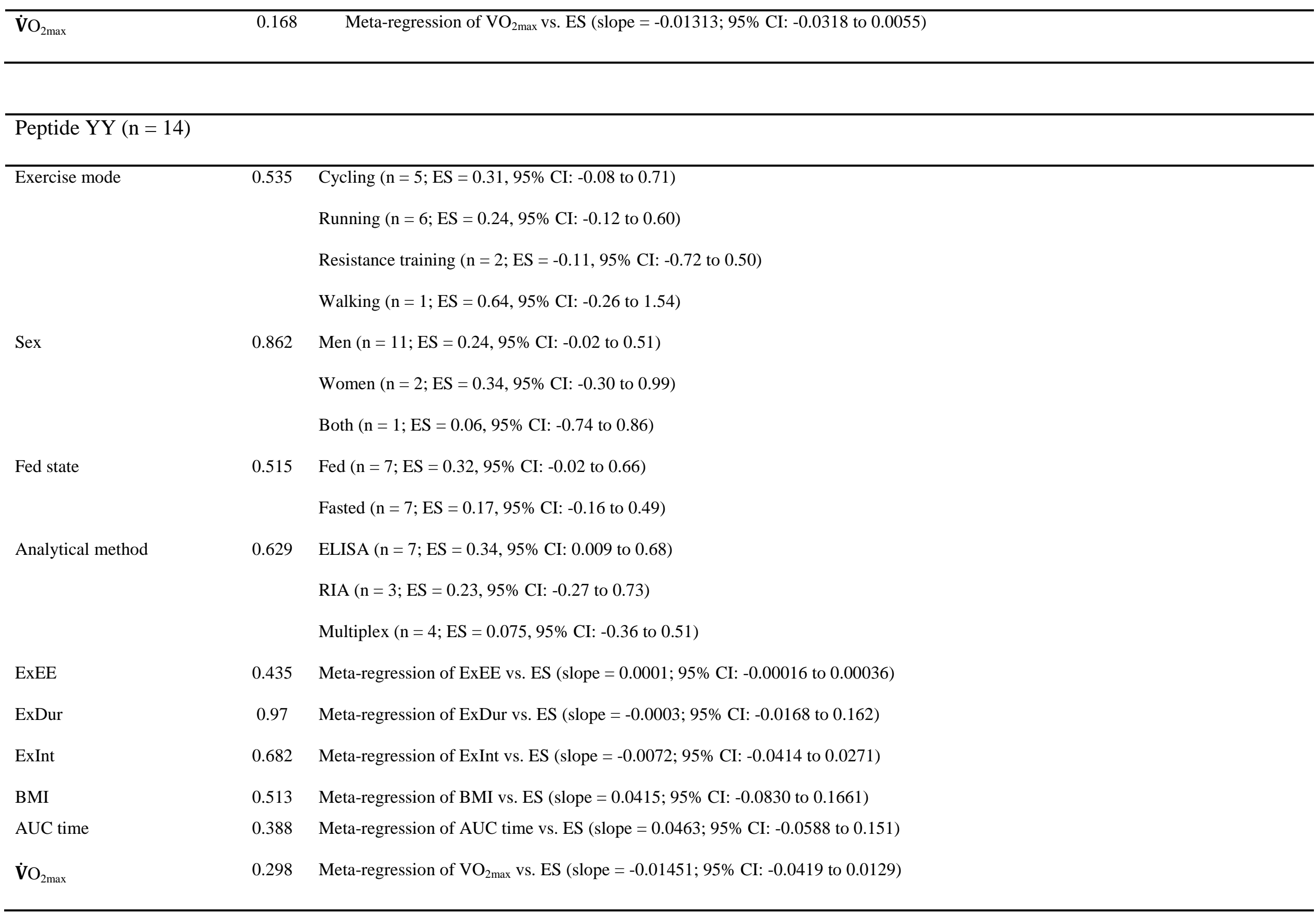


\#Test for statistical difference between moderator sub-group or significance of meta-regression (see text for explanations)

ES $=$ effect size $\quad$ AUC $=$ area under the concentration-time curve $\quad \dot{\mathrm{V}}_{2 \max }=$ maximal oxygen uptake $\quad$ ELISA $=$ enzyme-linked

immunosorbent assay RIA = radioimmunoassay $\quad$ ExEE = exercise energy expenditure ExDur = exercise duration $\quad$ ExInt $=$ exercise intensity

$\mathrm{BMI}=$ body mass index 